Nigerian Journal of Physiological Sciences 24 (1): 1 -6 @Physiological Society of Nigeria, 2009

Available online/abstracted at http://www.bioline.org.br/np; www.ajol.info/journals.njps; www.cas.org

\title{
COMPARATIVE STUDY OF ARTESUNATE, ACTS AND THEIR COMBINANTS ON THE SPERMATIC PARAMETERS OF THE MALE GUINEA-PIG
}

\begin{abstract}
A. W. OBIANIME AND J. S. APRIOKU
Department of Pharmacology, Faculty of Basic Medical Sciences, University of Port Harcourt, Choba, Rivers State, P.M.B. 5323, Nigeria. Tel: +234 (0) 8035082379 E-mail: sydaprio@yahoo.com

Summary: In this study, the comparative effects of half, normal and double clinical doses of artesunate; artesunate/sulfadoxine/pyrimethamine; artesunate/amodiaquine and their combinants (sulfadoxine/pyrimethamine and amodiaquine) on the semen parameters- total sperm count, motility, morphology, debris and premature/primordial cell count of the male guinea-pig were investigated. The agents caused significant $(\mathrm{p}<0.05)$ decreases in total sperm count and sperm motility, with increases in abnormal sperm cells (morphology), debris and premature sperm cells. The effects were maximal at the subclinical doses and synergistic in the ACTs, compared to those of the individual partner agents. Artesunate, amodiaquine and artesunate/amodiaquine caused 54, 28 and $84 \%$ decreases in total sperm count, with 13,31 and $64 \%$ decreases in sperm motility respectively. Conversely, the above drugs increased baseline morphology by 70,30 and $264 \%$ respectively. Similar synergistic responses were obtained with artesunate/sufadoxine/pyrimethamine. These results may be explained in terms of the oxidative effects of these agents, through generation of free radicals, resulting in pathological damage to testicular structure/function.
\end{abstract}

Keywords: Semen parameters, testis, spermatogenesis, Leydig cells, synergy and ACT.

\section{Introduction}

Malaria is caused by four species of Plasmodium- Plasmodium falciparum, Plasmodium vivax, Plasmodium ovale or Plasmodium malariae. Of these, $P$. falciparum accounts for majority of clinical cases and mortalities (Bozdech et al., 2003)

Effective treatment of malaria had been a great challenge to medicine and this has impacted enormously on man's health and economy (WHO, 1998; Sachs and Malaney, 2002). Treatment failures in malaria have been linked majorly to the development of resistance of the malaria parasite to standard antimalarial agents (Bruce-Chwatt, 1981; Markwalder and Meyer, 1982; Djimdé et al., 2001). Consequently, different antimalarial agents and regimens have been developed over the period to cope with this challenging problem (Bruce-Chwatt, 1981). The present choices of drugs are the artemisinin and its derivatives (White, 1997; Haynes, 2001). Also, better cure rates and clearance of the malaria parasite from the blood are achieved with the artesmisin-based combination therapies (ACTs), which include- artesunate/ amodiaquine, artesunate/sulfadoxine/pyrimethamine,

artesunate/mefloquine and artemether/ lumefantrine (Toure and Oduola, 2004; Nosten and White, 2007).

Furthermore, most antimalarial agents have been associated with male reproductive dysfunction in laboratory animals (Joshi et al., 1996; Adeeko and Dada, 1998; Parveen et al., 2003). Studies with mice/albino rats had shown that chloroquine, quinine
(Adeeko and Dada, 1998), halofantrine (Orisakwe et al., 2003) and artemsinins (Nwanjo et al., 2007) adversely affect sperm parameters. However, a comparative study on the effects of artemisinins, ACTs and combinants on these parameters to evaluate the therapeutic indices of ACTs had not been done. In an earlier study that we carried out, ACTs caused potentiation of the inhibitory actions of artemisinins and the combinant agents on serum testosterone. The aim of this study was therefore to investigate if there will be a positive correlative effect of the hormonal results with sperm parameters of the guinea-pig.

\section{Materials and Methods}

Drugs

All the drugs used in this study were obtained from the University of Port Harcourt Teaching Hospital (UPTH), Port Harcourt. The artemisinin derivative used was artesunate (Arinate), manufactured by ERFA, Rue des Cultivateurs 25, 1040 Brussels. The ACTs were artesunate/sulphadoxine/ pyrimethamine (Farenax) and artesunate/amodiaquine (Dart) manufactured by Swiss Pharma Nigeria Ltd, Lagos, Nigeria; while the combinant drugs were amodiaquine (Camoquine) manufactured by Pfizer Afrique de I'Quest BP 3857 - Dakar R.P. Senegal and sulfadoxine/pyrimethamine (Fansidar) by Swiss Pharma Nigeria Ltd, Lagos, Nigeria. The agents were dissolved in distilled water 
obtained from the Department of Chemistry, Faculty of Sciences, University of Port Harcourt and administered orally.

\section{Animals:}

Outbred strains of adult male guinea-pigs (GPs) of average weight $450 \pm 5 \mathrm{~g}$ were obtained from the animal house of the University of Port Harcourt, Nigeria and allowed to acclimatize for 14 days. The guinea-pigs were fed with alfalfa feeds daily ad libitum at a room temperature of $28^{\circ} \mathrm{C} \pm 2$ with 12 -h light/dark cycle. Water was given ad libitum.

\section{The effects on reproductive hormones \\ Protocol}

The animals were divided into six (6) groupsA, B, C, D, E and F of five animals each. The animals in group A (the control) were orally administered with distilled water, while those in group B were orally administered with $2 \mathrm{mg} / \mathrm{kg}$ body weight of artesunate 12-hourly for three days. Animals in group $\mathrm{C}$ were orally administered with $10 \mathrm{mg}$ base $/ \mathrm{kg}$ body weight of amodiaquine once daily for three days, while those in group D were orally given a single dose of $1.25 / 25 \mathrm{mg}$ base $/ \mathrm{kg}$ body weight of sulfadoxine/pyrimethamine. The animals in group $\mathrm{E}$ were orally dosed with $4 \mathrm{mg} / \mathrm{kg}$ body weight of artesunate and $10 \mathrm{mg}$ base $/ \mathrm{kg}$ body weight of amodiaquine once a day for 3 days. Finally, the animals in group $\mathrm{F}$ received $4 \mathrm{mg} / \mathrm{kg}$ body weight of artesunate, given once a day for 3 days and a single administration of $1.25 / 25 \mathrm{mg}$ base $/ \mathrm{kg}$ of sulfadoxine/pyrimethamine orally. These were all normal clinical doses of the agents (Barnes et al., 2006; Nosten and White, 2007).

These experiments with the antimalarial agents were carried out simultaneously with other sets of animals using half and double the normal clinical doses of the antimalarial agents.

At the end of the series of experiments (i.e each treatment course), the animals were sacrificed, the caudal epidermis was dissected out and semen was carefully extracted from the epididymis and analyzed for motility (calculated as percentage). The epididymal sperm count was performed with a haemocytometer and the morphology, debris and premature/primordial cell counts (expressed in percentages) were also noted.

\section{Statistical analysis}

Data were expressed as means \pm standard errors of mean. Comparisons between control and treated groups of guinea-pigs were performed with one-way analysis of variance (ANOVA), followed by Duncan's multiple comparison test. Statistical significance was set at $\mathrm{P}<0.05$.

\section{Results}

In $n=5$, the agents were generally toxic on the semen parameters of the guinea-pig. Total sperm count was significantly decreased $(\mathrm{P}<0.05)$ by all the agents used in this study at the different doses. The effects were more significant at subclinical and double clinical doses (Figs. 1a and b). At the subclinical dose, amodiaquine, artesunate and artesunate/ amodiaquine decreased the control sperm count from $55.50 \pm 3.8$ to $40.00 \pm 7.6,25.33 \pm 4.7$ and $9.00 \pm 1.5$ (i.e. 28,54 and $84 \%$ decreases) respectively (Fig. 1a). Similarly, the values for sulfadoxine/ pyrimethamine and artesunate/ sulfadoxine/pyrimethamine were $39.00 \pm 7.4$ and $18.67 \pm 0.33$ - representing 30 and $66 \%$ decreases (Figs. 1b). These values were very significant at $\mathrm{p}<0.05$ ANOVA. The effects were similar at the normal and double clinical doses, showing that the combination agents (i.e. ACTs) cause potentiation (synergy) of the adverse effects of the individual agents on total sperm.

In $\mathrm{n}=5$, sperm motility was also significantly decreased $(p<0.05)$ by the agents. This effect was dose-dependent with amodiaquine, artesunate, sulfadoxine/ pyrimethamine and artesunate/sulfadoxine/pyrimethamine, and nondependent with artesunate/amodiaquine. At the normal clinical dose, the control motility value was respectively decreased from $55.50 \pm 5.2$ to $48.33 \pm 1.70$, $38.33 \pm 4.4$ and $20.00 \pm 12.6$ by artesunate, amodiaquine and artesunate/amodiaquine, which represent 13, 31 and 64\% decreases (Fig. 2a). Similarly, the values obtained with sulfadoxine/pyrimethamine and artesunate/sulfadoxine/pyrimethamine were $44.00 \pm 7.0$ and $43.00 \pm 2.0$ (representing 21 and $23 \%$ decreases) respectively (Fig $2 b$ ). These values show synergistic response by the ACTs.

In $n=5$, the antimalarial agents caused increases in morphology, debris and primordial/premature sperm cells which were statistically significant $(p<0.05)$ at the three different doses. The effects were however most pronounced at the subclinical dose, with the agents (artesunate, amodiaquine, artesunate/amodiaquine) increasing the baseline morphology value from $13.75 \pm 2.4$ to $23.33 \pm 1.7$, $15.00 \pm 2.9$ and $50.00 \pm 11.5$ (representing 70, 30 and $264 \%$ increases) respectively and (sulfadoxine /pyrimethamine and artesunate/sulfadoxine/ pyrimethamine) to $18.33 \pm 6.0, \quad 30.00 \pm 2.9$ (representing 33 and $118 \%$ increases) respectively (Figs. 3a and b). These data show that the artemisinin combinations cause higher levels of toxicities on the morphology than the individual agents alone.

Furthermore, while artesunate, sulfadoxine/pyrimethamine and 
artesunate/sulfadoxine/ pyrimethamine caused dosedependent increases, artesunate/amodiaquine increased debris non-dose-dependently (Figs. 4a and b). Baseline debris value changed from $11.50 \pm 1.2$ to $34.33 \pm 1.9,18.00 \pm 1.0$ and $54.67 \pm 1.2$ when treated with artesunate, amodiaquine, artesunate/amodiaquine, resulting in 199, 57 and $375 \%$ increases respectively; whereas
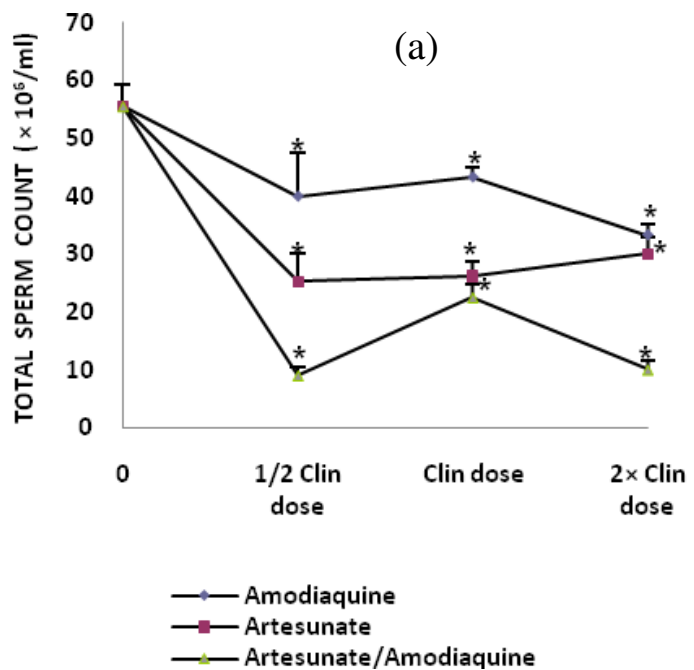

sulfadoxine/pyrimethamine

and artesunate/sulfadxine/pyrimethamine increased the control value to $19.00 \pm 1.4$ and $45.67 \pm 13.0$ (57 and $297 \%$ increases) respectively (Figs. $4 \mathrm{a}$ and b). In addition, the agents caused marked proliferation of premature/primordial cells at the various doses (not shown).

Fig. 1: The effects of antimalarial agents on the Total Sperm Count of the male GP. Data are expressed as mean \pm SEM, $n=5$; *Significantly different from control at $P<0.05$ ANOVA.
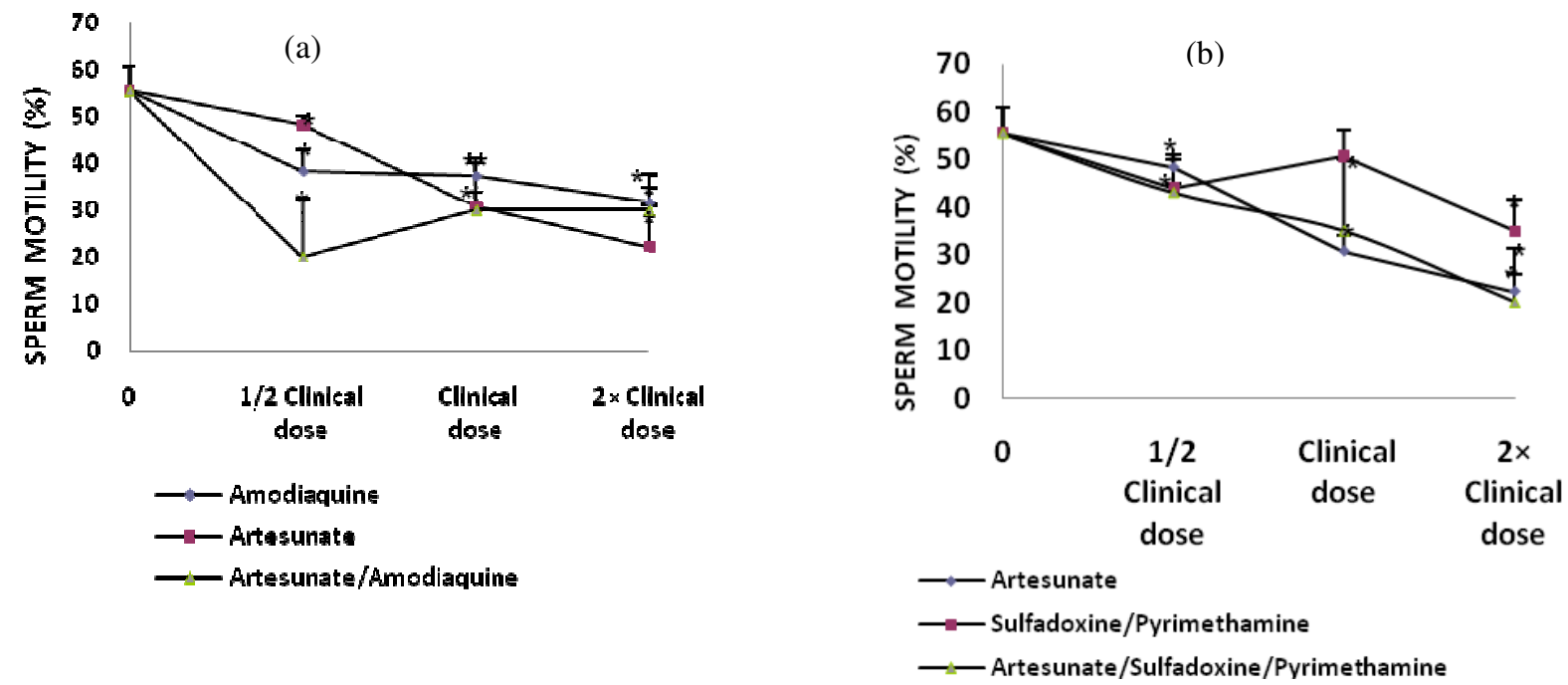

Fig. 2: The effects of antimalarial agents on the Sperm Motility of the male GP. Data are expressed as mean \pm SEM, $n=5$; *Significantly different from control at $P<0.05$ ANOVA. 

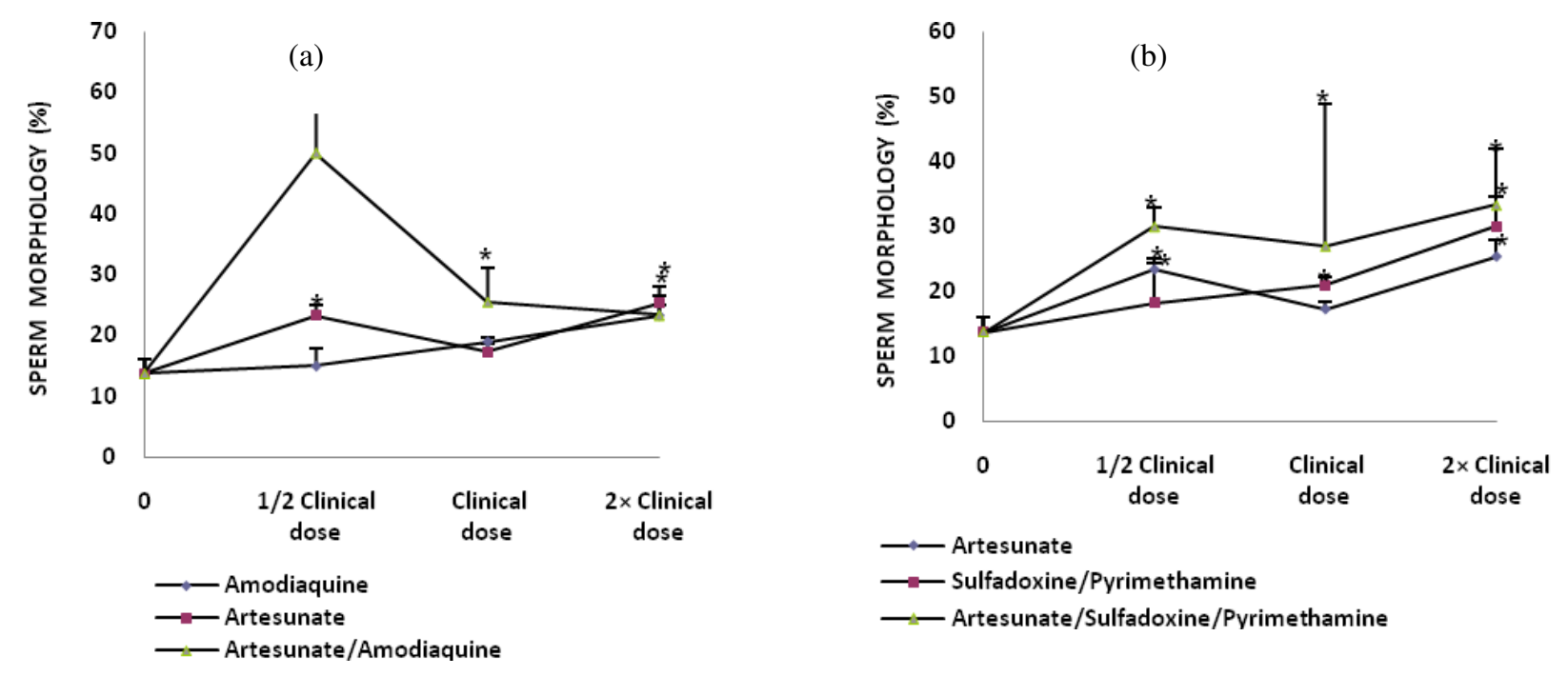

Fig. 3: The effects of antimalarial agents on the Sperm Morphology of the male GP. Data are expressed as mean \pm SEM, $n=5$; *Significantly different from control at $P<0.05$ ANOVA.

(a)
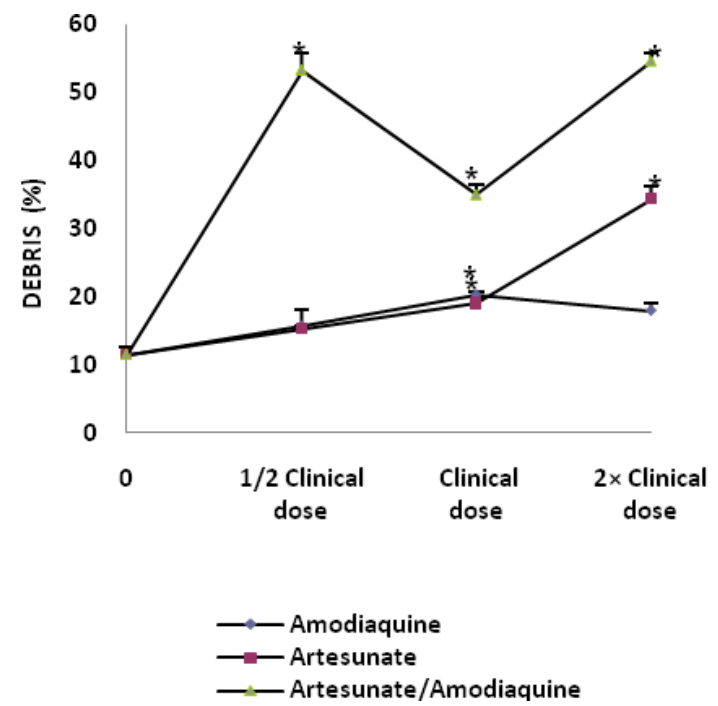

(b)
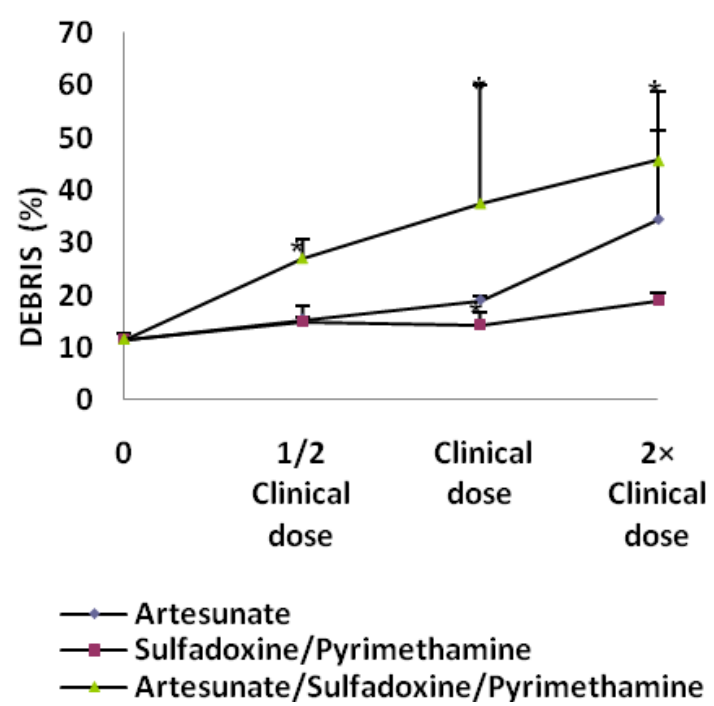

Fig. 4: The effects of antimalarial agents on the Sperm Debris of the male GP. Data are expressed asmean \pm SEM, $n=5$; *Significantly different from control at $P<0.05$ ANOVA. 


\section{Discussion}

In this study, the effects of different doses of artesunate, ACTs and their combinants on sperm parameters of the male guinea-pig were investigated. The sperm parameters investigated include- total sperm count, percentage motility, percentage morphology and percentage debris.

The testis, which is the major male reproductive organ, is responsible for sperm production or spermatogenesis. Spermatogenesis is the process of transformation of male germ cells into spermatozoa and occurs mainly in the avascular seminiferous tubules. It is a continual process involving mitosis of the male germ cells that undergo extensive morphological changes in cell shape and ultimately, meiosis to produce the haploid spermatozoa (Clermont, 1972; De Krester and Kerr, 1988). However, hormonal function is vital to normal spermatogenesis (Ganong, 2001). Spermatogenesis requires high intratesticular levels of testosterone, produced by the Leydig cells, which are scattered in a vascular, loose connective tissue between the seminiferous tubules in the interstitial compartment. Testosterone is particularly necessary to give growth and support to the Sertoli cells that contains the germ cells (Ganong, 2001).

In our earlier study on testicular hormones, artemisinin, ACTs and their combinants caused inhibitions of serum LH, FSH and testosterone levels in the male guinea-pig. This effect was most pronounced on testosterone, causing potentiations in the effects of the partner agents, especially at the subclinical dose.

In this study, the agents caused significant destructions of the semen parameters of the male guinea-pig which is consistent with precious studies (Orisakwe et al., 2003; Raji et al., 2005). Total sperm count and motility were highly reduced, while morphology and debris were greatly increased. Furthermore, the artemisinin-based combination agents caused synergistic results when compared with the individual agents in the therapy, showing that the ACTs may be more toxic on the testis compared with monotherapy with the individual agents in the combination. The effects were also more pronounced at the subclinical doses of the agents, which points out that the hormonal effects of these agents are positively correlated with their effects on sperm parameters. This is in agreement with the reports of Elkington and Blackshaw, (1974) and Ganong, (2001)

The effects observed in this study may be due to damages to the Leydig cells and seminiferous tubules responsible for testosterone and sperm productions respectively. Damage to Leydig cells will result in decreased testosterone production, which will in turn decrease spermatogenesis. Thus, decrease in testosterone production/release and damage to the seminiferous tubules may account for the massive reduction in total sperm count observed in this study. Furthermore, there was an increase in primordial/premature cells with maturation arrest and histopathological damage (not shown) in this study. This may be due to inhibition of meiosis of primary spermatocytes into secondary spermatocyctes and haploid spermatids (the meiotic cell division phase of spermatogenesis) and an increase in mitotic activity, thus resulting in the production of many premature spermatozoa and reduced matured spermatozoa. The increase in structural abnormality (morphology) and cell debris which is a measure of the level of contamination/metabolic wastes, may also be explained by the above, as well as direct destructive actions on sperm cells.

It has been shown that the proposed antiparasitic mechanism of action for the artesmisinins is through generation of free radicals- reactive oxygen species (Robert et al., 2000), with resulting in vitro and in vivo mitochondrial injury (Aitken et al., 2003). Furthermore, oxidative stress causes injury to genomic integrity in male germinal cells, resulting in infertility (Illingworth et al., 1996; Sharma and Agarwal, 1996). Thus, oxidative stress induced by these agents in seminal fluid, could directly or indirectly impair spermatogenesis and reproductive dysfunction observed in this study.

\section{Conclusion}

The present study has shown that artemisininbased combination treatments exert a potentiation/synergy of the toxicological effects of the component agents in the ACT on testicular function in the guinea-pig, which may be deleterious to the reproductive health of the animal. The results of this study also have a positive correlation with our earlier hormonal study, which shows decrease in the serum level of testosterone. The experiment is being carried out in humans to see if these results will be reproducible in humans.

\section{Acknowledgement}

We are grateful to Mrs. Matilda Deeko and Mr. Joshua Isirima of the Department of Pharmacology, University of Port Harcourt for their technical assistance. We also thank Mr. Maxwell Azubuike of the Department of Mathematics and Statistics, University of Port Harcourt for his assistance in the statistical analysis. 
A. W. Obianime and J. S. Aprioku

\section{References}

Adeeko, A. O and Dada, O.A. (1998). Chloroquine reduces fertilizing capacity of epididymal sperm in rats. Afr. J. Med Sci. 27: 63-64

Aitken, R. J., Baker, M. A. and Sawyer, D. (2003). Oxidative stress in the male germ line and its role in the aetiology of male infertility and genetic disease. Reprod. Biomed. Online. 7:65-70

Barnes, K. I., Little, F., Smith, P. J., Evans, A., Watkins, W.M. and White, N.J. (2006). Sulfadoxine-pyrimethamine pharmacokinetics in malaria: pediatric dosing implications. Clin Pharmacol. Ther. 80: 582-596.

Bozdech, Z., Llinas, M., Pulliam, B. L., Wong, E. D., Zhu, J. and DeRisi, J. L. (2003). The transcriptome of the intraerythrocytic developmental cycle of Plasmodium falciparum. PLOS Biology. 1: 85-100.

Bruce-Chwatt, L. J. ed. (1981). Chemotherapy of malaria, 2nd ed. World Health Organization, Geneva.

Christensen, A. C. (1975). Leydig cells. In: Handbook of physiology, P.O. Greep and E. B. Astwood (eds). Washington D.C: American Physiological Society. pp 165-172.

Clermont, Y. (1972). Kinetics of spermatogenesis in mammals: seminiferous epithelium cycle and spermatogonia renewal. Physiol. Rev. 52: 198 235.

De Krester, D. M. and Kerr, J. B. (1988). The cytology of the testis. In: The Physiology of reproduction Knobil E, and Neill J. 9eds) 1: 837 932.

Djimdé, A., Doumbo, O.K., Cortese, J.F., Kayentao, K., Doumbo, S., Diourté, Y., Dicko, A., Su, X.Z., Nomura, T., Fidock, D.A., Wellems, T.E., Plowe, C.V. and Coulibaly, D. A molecular marker for chloroquine-resistant falciparum malaria. N. Engl. J. Med. 344(4):299-302.

Elkington, J.S.H. and Blackshaw A.W. (1974): Studies in testicular function. I. Quantitative effects of FSH, LH, testosterone and dihydrotestosterone on restoration and maintenance of spermatogenesis in the hypophysectomized rat. Aust. J. Biol. Sci. 27:4757

Ganong, W.F. (2001). Review of Medical Physiology. 20th ed. New York: Lange. p 239 - 41

Haynes, R.K. (2001). Artemisinin and derivatives: The future for malaria treatment? Curr Opin Infect Dis. 14: 719-726.
Illingworth, P.J., Groome, N. P., Byrd, W., Rainey, W. E., McNeilly, A. S., Mather, J.P. and Bremner, W. J. (1996). Inhibin-B. A likely candidate for the physiologically important form of inhibin in men. J. Clin. Endocrinol. Metab.. 81: 1321-1325.

Joshi, A. R., Ahamed, R. N., Pathan, K. N. and Manivannah, B. (1996). Effect of Azadirachta indica leaves on the testis and its recovery in albino rats. Ind. J. of Exp Bio.34: 1091-1094.

Markwalder, K.A., Meyer, H.E. (1982). Possible sulfadoxine-pyrimethamine resistance in Plasmodium falciparum malaria from Kenya (letter). Trans. R Soc. Trop. Med. Hyg. 76:281.

Nosten, F. and White N.J. (2007). Artemisinin-based combination treatment of Falciparum malaria. Am. J. Trop. Med. Hyg. 77(6): 181-192.

Nwanjo, H. U., Iroagba, I. I., Nnatuanya, I. N. and Eze, N. A. (2007). Antifertility activity of dihydroartemisinin In male Albino rats. The Internet J. Endocrinol. 4(1)

Orisakwe, O. E., Obi, E. and Udemezue, O. O. (2003). Effect of halofantrin on testicular architecture and testosterone level in guinea pigs. Eur. Bull. drug Res. 11: 105-109

Parveen, S., Das, S., Kundra, C.P., and Pereira, B.M.I. (2003). A Comprehensive evaluation of the reproductive toxicity of Quassia amara in male rats. Reprod. Toxicol. 17: 45-50.

Raji, Y., Osonuga, T.O., Akinsomisoye, O.S., Osonuga, O.A., and Mewoyeka O.O. (2005). Gonadotoxicity evaluation of oral artemisinin derivatives in male rats. J. Med. Sci. 5(4): 303306.

Robert, K.M., Daryl, K.G., Peter, A.M. and Victor, W.R. (2000). Harper's Biochemistry (25th ed.). Appleton: Lange. pp. 169- 170; 648-649.

Sachs, J. and Malaney, P. (2002). The economic and social burden of malaria. Nature. 415: 680 -685

Sharma, R. K. and Agarwal, A. (1996). Role of reactive oxygen species in male infertily. Urol. 48: 835-850.

Toure, Y. T. and Oduola, A. (2004). Malaria. Nature. 2: $276-277$.

White, N. J. (1997). Assessment of the pharmacodynamic properties of anti-malaria drugs in vivo. Antimicrobial Agents for Chemotherapy. 41: 1413-1422.

World Health Organization. Malaria Chemotherapy. Tech. Reg. Ser. Geneva. 1998. 